\title{
Some Advice for Minorities and Women on the Receiving End of Health-care Disparities
}

\author{
Augustus A. White III \\ Received: 9 October 2013 /Revised: 9 January 2014 / Accepted: 13 January 2014 / Published online: 12 February 2014 \\ (C) Cobb/NMA Health Institute 2014
}

\begin{abstract}
The pervasive, distressing realities of health-care disparities were well documented in the milestone publication by the Institute of Medicine in 2003. This work reviewed numerous articles published in peer-reviewed journals showing disparities in health care for a number of groups in our society, including African Americans, Native Americans, Asian Americans, Latinos, and women. These disparities are caused by conscious and subconscious bias, stereotyping, racism, and sexism in our society. Although not enough, there are numerous programs and activities designed to eliminate health-care disparities. Health literacy is one element that is helpful in improving anyone's health care. For those who are at risk to experience health-care disparities, a patient education program is thought to be helpful, although presenting without evidence basis. If patients at risk for health-care disparities can be educated to have the knowledge, skills, and attitudes to negotiate a system wrought with disparities, this would be helpful in diminishing the existence of these disparities. Fifteen specific recommendations are offered which together are expected to provide considerable help in diminishing health-care disparities in the at-risk patient population. A brief explanation of the reason and rationale for the recommendations is offered as needed. A presentation of the patient's rights and responsibilities is provided to help patients cope in this current medical environment. These rights and responsibilities are wellregarded examples of current best practices.
\end{abstract}

Keywords Advice to patients · Health care disparities . Conscious bias $\cdot$ Subconscious bias $\cdot$ Stereotyping $\cdot$ Racism . Health literacy $\cdot$ Patient education $\cdot$ Patient rights $\cdot$ Patient responsibilities · Ambient racism · Distrust · Teach back . Humanize $\cdot$ Interpreter

\section{A. A. White III $(\bowtie)$}

Culturally Competent Care Education Program, Harvard Medical School, Landmark East 2N07, 401 Park Drive, Boston, MA 02215, USA

e-mail: augustus_white@hms.harvard.edu
"Of all the forms of inequality, injustice in health care is the most shocking and inhumane."

Martin Luther King, Jr.

\section{Introduction and Background}

Dr. King, of course, was a very wise man. But given his legendary struggle for equality and fundamental human rights, it may seem a little odd that he would place inequality in health care at the very top of the list of injustices - "the most shocking and inhumane," as he put it.

But think for a moment. When in the normal course of our lives, are we at our most vulnerable? When are we most frightened? When are we in most pain? The answer is - when we are suffering from illness or injury. And it is exactly then that we must go for help to someone we may know only slightly or who may be a complete stranger to us. That person may come from a different culture; he or she might speak differently. If we are not native English speakers, we may have difficulty understanding what that person is telling us even at the most basic level. In the best of circumstances, he or she will be using a language we are likely not be very familiar with - the language of medicine. We are faced with all these when we are in distress physically and, very likely, emotionally as well. It is in these difficult circumstances that injustice and inequality strikes most egregiously.

Injustices in health care are commonly described as disparities. These disparities are pervasive, and, sometimes, a harsh reality for many of us. Peer review journals confirm a substantial inequality in health care for minorities and women in America today. The infant mortality rate for Blacks is more than twice that for whites [1]. African Americans receive fewer cardiac catheterizations [2], fewer angioplasties, fewer bypass surgeries [3], fewer kidney transplants [4], and fewer lung cancer surgeries [5]. African Americans [6] and Hispanic Americans [7] with 
fresh long bone fractures receive significantly less pain medication as compared with whites. In addition, pharmacies in predominantly nonwhite neighborhoods of New York City do not stock sufficient medications to treat patients with severe pain adequately [8]. African Americans received fewer total joint replacements [9] and fewer procedures for open reduction and internal fixation of femoral fractures [10]. African Americans receive more hysterectomies [10, 11], more amputations [12], and more bilateral orchiectomies [13]. The average American life expectancy in 2001 was 77.2 for African Americans, and whereas for whites, it was 77 years [14]. The death rate for nine of the top ten causes of death in America is at least 1.5 times greater for Blacks than for whites $[1,15]$.

One might ask, "Why is this?" How can these realities be so striking, pervasive, extensive, and persistent?

There are a number of factors behind such shocking facts. We know from research in psychology and other disciplines that unconscious bias is an ever present and powerful reality impacting many of our day-to-day decisions, large and small. Physicians are not exempt from this reality. Moreover, we know that the likelihood of unconscious or subconscious factors affecting decision making is much greater for individuals under stress [16], which typically include doctors. The list of "doctor stressors" is a long one: rushed schedules, sky-high debt burdens from medical school, the need to keep up with an avalanche of research and clinical studies, ever mounting medical insurance costs, and that is the short list. As a result, physicians are especially prone to the impact of the subconscious, which includes biases that run beneath the surface and awareness of our mental lives. And yes, some caregivers still carry conscious prejudices as they practice, though that may be reduced from what it used to be.

There is another context in which health-care disparities occur. This has to do with a tendency for stereotyping on the part of caregivers. People have a propensity to stereotype; it is a universal human trait, and often damaging or dangerous for those who are stereotyped. "Driving while Black" is a danger. "Being a patient while Black" can be one, too.

A third mechanism that can contribute to health-care disparities in the patient-doctor interaction is the harsh and still ubiquitous ambient racism [17]. Institutions, businesses, schools and other social environments incorporate in their practices histories of racial prejudices that remain, even given efforts to eliminate them. Clinics and hospitals are far from immune to these residual and difficult to extract biases [18].

Subconscious and conscious bias, stereotyping, and ambient racism affect health care [19]. They are, simply, realities that minorities must take into account. These are discussed in detail in Seeing Patients: Unconscious Bias in Health Care [17]. Patients who are aware of this can proceed realistically in their interactions with the health-care system. The purpose of this awareness is not to create or magnify distrust, but to help develop practices that will result in the best possible outcomes when we need medical treatment or health maintenance.
It is also good to remember that distrust on anyone's part is a problem, patients' as well as doctors'. One factor in the medical care equation is that patients, most especially in crosscultural patient-doctor interactions and most especially when the patient is African American, do have a tendency for distrust. Doctors are aware of this. It is recognized in the medical literature; it comes up in doctors' conversations with each other. The renowned African-American psychiatrist Dr. Price Cobbs famously said in his book, Black Rage [20], "If you're Black in America, and you're not paranoid... you must be crazy." But bringing any hint of paranoia with you into the examining room will not help produce good results. Remember, doctors are as patients are. They will react to the way you treat them just as you react to the way they treat you.

Hopefully this background will alert, focus, motivate, and help the reader to develop knowledge, attitudes, and skills that will result in a good outcome when the patient encounters caregivers in the current US health-care system. The intended outcome is for the patient to be alert, savvy, sophisticated, and wise, but not with a chip on the shoulder. A chip is not going to help get the kind of care that the patient deserves.

\section{The Advice}

Consider the following preamble. As with any human interaction, one is encouraged to be polite, respectful, but also direct. Know your rights. In the patient-doctor encounter, remind yourself of the obvious: it is your health, perhaps your life, that is on the line, no one else's. What you want is the very best care that you can get without any confrontation or hostility. We want you to be empowered because you do have rights as a patient, and you should be aware of them. We want to help you to be aware of them.

You have a right as a patient to receive equitable care, to receive good care. You should not have to demand good equitable care, but you should get it by merely being present, pleasant, and cooperative. There are a number provisions in the US Constitution, federal civil rights statutes, state statutes, and professional association and accrediting standards that prohibit a hospital or doctor from discriminating against a patient based on race. To support this, you may cite the 14th Amendment (guaranteeing equal protection of law), title VI of the Civil Rights Act of 1964, the reconstruction Civil Rights Acts, 42 U.S.C. Sections 1981.982 and 1983-among others. ${ }^{1}$

- Read the general guidelines on "Getting the Most Out of Your Doctor's Visit" [21].

\footnotetext{
${ }^{1}$ Based on a consultation in Dec. 19, 2013 with Frank M. McClellan, Professor of Law Emeritus, Co-Director Temple University Center for Health Law, Policy and Practice, James E. Beasley School of Law, Temple University, Philadelphia, PA
} 
- Cooperate and respond to demographic questionnaires collected by the health facility. Institutions collect this data, so that it will be possible to review the care received by various demographic groups: racial, ethnic, gender, and LGBT and others. This is important because it can uncover inequitable care when it occurs and hopefully lead to successful remedies.

- Be sure to complete Patient Satisfaction forms. Such feedback is enormously important. Some institutions will give serious considerations to your response and will seek to improve when the patient interactions in which they can do better are pointed out. If they do not have your feedback, they will not have the incentive nor the information with which to address inequitable unsatisfactory care.

- Networking is useful in two ways. First, it allows patients to learn the good and the bad about how they may be treated in a given facility. We, at-risk people, can oftentimes accurately sense conscious and unconscious bias on the part of caregivers. Networking activities can provide useful positive and negative feedback which can inform and incentivize the various treatment institutions. Moreover, social media communications greatly facilitates these important communications, activities, and mechanisms.

- Know your patients' rights. Some health facilities publish a list of patients' rights. Ask for a copy. If they are not published in the facility, you can find them online. See www.nationalhealthcouncil.org/.

- Become health literate. Here is one of the most important measures you can take: Study your symptoms and your disease(s) on WebMD or the Mayo Clinic.com website or some other reliable source of medical information and learn about your disease. This will help you to interact with your physician, ask questions more effectively, and get better care.

- Ask questions. Ideally, write down your questions before you go into the physician's office. If helpful, read them when you have the opportunity during the visit. If you do not have a chance to write them down, ask them anyway. When in doubt, in any patient-doctor interaction, if you are anxious or worried or confused, ask questions. Repeat: ask questions.

- Do a "teach back." This more structured way of asking questions can clarify your health status, the plan for addressing issues, and help establish your role as an active participant in your care. At some point before the visit is over, say "Doctor, may I just take a moment to see if I understand what my illness is, what we're doing about my illness, and the reasons for what we're doing?" Then review the visit. "Doctor, please let me see if I understand my problem and what we're going to be doing to solve it." Then, tell the doctor. The doctor will then tell you if you got it right and correct you as and if needed. You will then explain things again to the doctor who will once again correct you if needed. This process (teach back) continues until it is clear that you understand the doctor's instructions and/or prescriptions. Some doctors have had training and are instructed to initiate this teach back activity. But remember, if the doctor does not initiate the teach back, you should initiate it.

- If you sense a need, do what we call a "reality check." True, we want to be cautious about our distrust, but if you sense, for whatever reason, that you are not receiving adequate care, that in fact, you are receiving disparate care, I repeat, for whatever reason - whether it is because you encountered lack of attention, discourtesy, prejudice, disrespect-we recommend the following. Relax, focus, look at the physician, and say, "Doctor, I came here because of your reputation/the reputation of this facility as a place where I would receive good care. Doctor, I have to be frank and tell you that I feel that I'm not receiving good care. I'm not sure why. I'm not sure if you have not treated African-American patients before, (or elderly patients before, or seriously overweight patients before), but I feel somehow we're not moving forward together and I'm not receiving the care I need and deserve."

This can be done forthrightly and respectfully and is $100 \%$ within your rights. If the doctor responds with an apology or some other positive response such as, "That was not my intent, I do want to provide good care for you," that is a good outcome. You, the patient, may then say, "Doctor, let's move forward and see how we can work together effectively." If you, the patient, have a special specific complaint, then express that again or add that to what you have already said. If the doctor responds in an unconcerned, detached, offensive, or aggressive manner, then I think you should fill out your Doctor Satisfaction form and look for another doctor. If the doctor makes an attempt to adjust and expresses a desire to move forward and provide the care that you expected, then it makes good sense to continue with that doctor as long as you feel you are making progress. Again, this is entirely within your rights. Remember that it is your health that is on the line. You must advocate for yourself.

- Try to humanize your doctor/your caregiver. This is something we recommend physicians do as well when treating their patients, as an attempt to enrich the patient-doctor relationship and develop a more collaborative, cooperative partnership, which will result in more effective care. Two human beings, the caregiver and the patient, constitute this relationship. Any personal exchange can work toward establishing a human connection - which is always helpful in furthering the professional connection. Ask about family, children, grandchildren, or ask about the weather. If the doctor asks how you are, ask in turn how he or she is. Be interested. By all means seek to humanize your doctor. 
Doing that will help him or her to focus on you as a fellow human person.

- Perhaps you can research your caregiver ahead of time, either online or through word of mouth. You may find you have things in common: maybe you are from the same city or region, perhaps you went to the same school, or to a similar church, maybe you played the same sports, or have a particular overlapping interest in art or music — anything that you can relate to, however briefly, that engages experience in common.

- If you are comfortable sharing your health information, by all means, take a friend and/or a relative with you and ask the doctor if he or she is comfortable having your friend be present because it is important for you. That person is another set of ears. If what is going on is complicated, he or she might take notes or may simply remind you of things that you would like to include in your discussion with the doctor. It is a good check, and it lets the doctor know that at least one other person cares about you. This "buddy visit" tends to add confidence and security in any circumstances.

- If you have a negative, unsatisfactory, unpleasant, inadequate patient-doctor interaction, make sure to report the incident to someone in a supervisory capacity at the hospital or clinic, preferably in person or by telephone or by mail as a last choice. Report to the highest-ranking person you can contact. Simply explain your disappointment, report that you are upset, and explain the reason for it. This will not erase your experience, but it will give you a sense of satisfaction in that you are doing something about the problem, and in many instances, it will be helpful to your fellow patients as your complaint is addressed with by the institution and the caregiver involved. If not satisfied, seek a facility with a better reputation for equitable care.

- If surgery is in the picture and you are inclined toward surgery and your caregiver is pushing against it, get a second opinion. If you are inclined not to have a surgical procedure and your caregiver is pushing for you to have it, get a second opinion. Actually, if a major surgery is in the picture, get a second opinion regardless of your inclination to proceed or not.

- If in any doubt or difficulty with English proficiency, ask about having an interpreter [21].

\section{A Parting Observation}

You cannot control health policy for the nation nor for your local health facility. You cannot control health insurance. You cannot control the doctors, the nurses, or the staff in your health facility, but you can control yourself. The most important benefit of all to your health is your health literacy. And that is under your own control. Know as much as you can about your problem, your symptoms, and how you can most effectively interact with your health care provider!

Hopefully some, if not all, of the suggestions made here will be helpful. Keep your chin up, keep your head up, keep your pride up, know your rights, and be assertive and persistent in search of collaborative mutually respectful arrangements with your caregivers.

The following is the standard list of patient rights and responsibilities from the Beth Israel/Deaconess Medical Center, a Harvard Medical School teaching hospital [22].

\section{Your Rights as a Patient [22]}

Our statement of patients' rights, incorporating state and federal law, describes the medical center's commitment to protecting your rights.

1. You have the right to receive medical care that meets the highest standards of BIDMC, regardless of your race, religion, national origin, any disability or handicap, gender, sexual orientation, gender identity or expression, age, military service, or the source of payment for your care.

2. You have the right to receive visitors of your choosing that you (or your support person, where appropriate) designate, including a spouse, domestic partner (including same-sex domestic partner), or another family member or a friend.

3. You have the right to prompt, life-saving treatment in an emergency without discrimination based on economic status or source of payment, and to treatment that is not delayed by discussion regarding the source of payment, except in an emergency.

4. You have the right to be treated respectfully by others and to be addressed by your proper name without undue familiarity.

5. You have the right to privacy within the capacity of the medical center.

6. You have the right to seek and receive all the information necessary for you to understand your medical situation. You have the right to know who will perform an operation or a test and to receive a full explanation of the details in advance, in order for you to exercise your right to give informed consent or elect to refuse.

7. You have a right to know the identity and the role of individuals involved in your care.

8. You have a right to a full explanation of any research study in which you may be asked to participate. 
9. You have the right to leave the medical center even if your doctors advise against it, unless you have certain infectious diseases that may influence the health of others, or if you are incapable of maintaining your own safety or the safety of others, as defined by law.

10. You have the right to access your medical record.

11. You have the right to inquire and receive information about the possibility of financial assistance.

12. You are entitled to know about any financial or business relationships the medical center has with other institutions, to the extent the relationship relates to your care or treatment.

13. You have the right not to be exposed to the smoking of others.

14. You have the right to take part in decisions relating to your health care.

15. You have the right to appropriate assessment and management of pain.

16. You have the right as a patient who may have limited English proficiency to have access, free of charge, to meaningful communication via a qualified interpreter either in person or by phone, as deemed appropriate.

17. You have the right to receive information about how you can get assistance with concerns, problems, or complaints about the quality of care or service you receive and to initiate a formal grievance process with the medical center or with state regulatory agencies. Should you have concerns, problems, or complaints about the quality of care or service that you are receiving, you are encouraged to speak to the providers directly involved in your care.

\section{Your Responsibilities as a Patient [22]}

1. Provide accurate and complete information regarding your identity, medical history, hospitalizations, medications, and dietary supplements (herbal and other nutritional supplements).

2. Follow treatment plans recommended by physicians and other health-care providers working under the attending physician's direction.

3. Participate and collaborate in your treatment and in planning for posthospital care.

4. Be part of the pain management team.

5. Be considerate and respectful of other patients and medical center personnel.

6. Follow medical center rules and regulations, including those that prohibit offensive, threatening, and/or abusive language or behavior, and the use of tobacco, alcohol, or illicit drugs or substances.
7. Provide the medical center with a copy of any advance directive or health-care proxy designation you have prepared.

8. Provide accurate and complete financial information and work with the medical center to ensure that financial obligations related to your care are met.

Acknowledgments Some portions of this article first appeared in the Boule Journal. See White, AA, III, "Preventing Health-Care Disparities: Advice for Minorities and Women", Boule Journal 77 (3): 23-25, 2013. Thanks to Nancy Ferrari for her editorial contributions and to Yolanda Bauer for her general administrative assistance. The author wishes to also acknowledge the following support: Dr. Mark Bernhardt, Beth Israel Deaconess Medical Center, Department of Orthopaedic Surgery, Blue Cross Blue Shield of Massachusetts, Culturally Competent Education Program, Harvard Medical School, Rodger L. and Gloria F. Daniels Charitable Foundation (Richard J. Hindlian, Co-Trustee), J. Robert Gladden Orthopaedic Society, Arthur and Barbara Higgins Charitable Foundation, Dr. Melvin Law, The Macy Foundation, Massachusetts General Hospital, Department of Orthopaedic Surgery, McKesson Foundation, Reverend Willie and Mrs. Anne Naulls, Macey Russell, and Zimmer Holdings Inc.

Conflict of Interest Dr. White declares that he has no conflict of interest.

\section{References}

1. Smedley B, Stith A, Nelson A. Unequal treatment: confronting racial and ethnic disparities in health care. Washington: The National Academies; 2003.

2. Schulman KA, Berlin JA, Harless W, Kerner JF, Sistrunk SS, Gersh BJ, et al. The effect of race and sex on physicians' recommendations for cardiac catheterization. N Engl J Med. 1999;340: 618-26.

3. Ayanian JZ, Udvarhelyi IS, Gatsonis CA, Pa-Shos CL, Epstein AM. Racial differences in the use of revascularization procedures after coronary angiography. JAMA. 1993;269:2642-6.

4. Ayanian JZ, Cleary PD, Weissman JS, Epstein AM. The effect of patients' preferences on racial differences in access to renal transplantation. N Engl J Med. 1999;341:1661-9.

5. Bach PB, Cramer LD, Warren JL, Begg CB. Racial differences in the treatment of early-stage lung cancer. N Engl J Med. 1999;341:11982005.

6. Todd KH, Deaton C, D'Adamo AP, Goe L. Ethnicity and analgesic practice. Ann Emerg Med. 2000;35:11-6.

7. Todd KH, Samaroo N, Hoffman JR. Ethnicity as a risk factor for inadequate emergency department analgesia. JAMA. 1993;269: 1537-9.

8. Morrison RS, Wallenstein S, Natale DK, Senzel RS, Huang LL. "We don't carry that" - failure of pharmacies in predominantly nonwhite neighborhoods to stock opioid analgesics. N Engl J Med. 2000;342: 1023-6.

9. Weinstein J, Birkmeyer NO. The Dartmouth atlas of musculoskeletal health care. Chicago: American Hospital Association; 2000.

10. Mort EA, Weissman JS, Epstein AM. Physician discretion and racial variation in the use of surgical procedures. Arch Intern Med. 1994;154:761-7.

11. Kjerulff KH, Guzinski GM, Langenberg PW, Stolley PD, Moye NE, Kazandajian VA. Hysterectomy and race. Obstet Gynecol. 1993;82: 757-64. 
12. Guadagnoli E, Ayaman JZ, Gibbons G, McNeil BJ, LoGerfo FW. The influence of race on the use of surgical procedures for treatment of peripheral vascular disease of the lower extremities. Arch Surg. 1995;130:381-6.

13. Gornick ME, Eggers PW, Reilly TW, Mentnech RM, Fitterman LK, Kucken LE, et al. Effects of race and income on mortality and use of services among Medicare beneficiaries. N Engl J Med. 1996;335: 791-9.

14. Arias E, Anderson RN, Hsiang-Ching K, et al. Deaths: final data for 2001. National Vital Statistics Reports, vol 52, no. 3. Hyattsville: National Center for Health Statistics; 2003.

15. Geiger HJ. Racial and ethnic disparities in the U.S. Health Care System: physician bias, patient choice, In: First annual meeting, International Society on Equity in Health, June 30, 2000, Havana, Cuba

16. Burgess D, van Ryn M, Dovidio H, Saha S. Reducing racial bias among health care providers: lessons from social-cognitive psychology. J Gen Intern Med. 2007;22:882-7.
17. White III AA, Chanoff D. Seeing patients: unconscious bias in healthcare. Cambridge: Harvard University Press; 2011.

18. White 3rd AA, Shands Jr AR. Lecture: our humanitarian orthopaedic opportunity. J Bone Joint Surg Am. 2002;84:478-84.

19. Green AR, Carney DR, Pallin DJ, et al. Implicit bias among physicians and its prediction of thrombolysis decisions for black and white patients. J Gen Intern Med. 2007;22:1231-8.

20. Grier WH, Cobbs PM. Black rage: two black psychiatrists reveal the full dimensions of the inner conflicts and the desperation of black life in the United States. New York: Basic Books; 1992.

21. American Academy of Orthopaedic Surgeons. Getting the most out of your doctor's visit. OrthoInfo. 2009. http://orthoinfo.aaos.org/ topic.cfm?topic=A00561. Accessed January 2014.

22. Beth Israel Deaconess Medical Center. Patients' rights and responsibilities. 2013. http://www.bidmc.org/Patient-and-VisitorInformation/Preparing-for-Your-Visit/Patients-Rights-andResponsibilities.aspx. August 2013. 